\title{
Characterization of Gross Domestic Expenditure on R\&D in Latin American countries during 2008-2017
}

\author{
${ }^{1}$ Marisabel Luna Cardozo, ${ }^{2}$ Aura Guerrero-Luzuriaga, ${ }^{3}$ David G. Miranda, ${ }^{4}$ Hugo Ricardo \\ Prado López, ${ }^{5}$ Michael Lincold Trujillo Pajuelo, ${ }^{6}$ Gregorio Arroyo Japura \\ ${ }^{1}$ Universidad Nacional Experimental Politécnica Antonio José de Sucre, Barquisimeto, Venezuela \\ ${ }^{2}$ Universidad Católica de Cuenca, Ecuador \\ ${ }^{3}$ Universidad SEK, Santiago de Chile, Chile \\ ${ }^{4}$ Universidad Cesar Vallejo, Perú \\ ${ }^{5}$ Universidad Privada del Norte, Perú \\ ${ }^{6}$ Universidad Nacional de Moquegua , Perú \\ ${ }^{1}$ mluna@unexpo.edu.ve, ${ }^{2}$ ing.auragl@gmail.com, ${ }^{3}$ miranda.politicas@gmail.com, ${ }^{4}$ pedropablo1956@yahoo.es, \\ ${ }^{5}$ mtpabogado01@gmail.com, ${ }^{6}$ garroyoj4@ hotmail.com
}

Article History: Received: 11 January 2021; Accepted: 27 February 2021; Published online: 5 April 2021

\begin{abstract}
Gross domestic expenditure on R\&D is one of the most analyzed indicators in terms of growth and economic development of a country. Improving this indicator would lead to the achievement of the SDG that UN Member States adopted in 2015, which responds to build resilient infrastructure, promote inclusive and sustainable industrialization, and foster innovation. In this research, a descriptive analysis of the GDE on R\&D indicator of Latin American countries, in the period 2008 - 2017, has been carried out in order to analyze and compare it. Firstly, information is presented on the GDE on R\&D indicator. Then, the analysis and comparison of the indicator among Latin American countries is shown. In the same way, for the countries that obtain better results, they are compared with the values of the indicator of other countries of Ibero-America and North America. Brazil is the only Latin American country that presents the highest average value of the indicator (0.012), above the average value of Latin American and Caribbean countries, and even of Ibero-American countries.
\end{abstract}

Keywords: GDE, Gross Domestic Expenditure on R\&D, Latin American countries, Research and Development.

\section{Introduction}

Innovation is a factor that determines the economic growth of a country based on R\&D [1], [2], [3]. Hence the interest in measuring and evaluating Gross Domestic Expenditure (GDE) on R\&D. This expenditure refers to the current and capital expenditure on R\&D, in USD constant prices, as a percentage of GDP, made by companies, laboratories and research institutes, public or private, in a country. It uses base year 2010 and Purchasing Power Parities (PPPs) [4] as a measure of sustained economic growth [5], [6].

In 2017 (with $4.58 \%$ as GDE on R\&D value) Israel is positioned with the highest value in the world, in contrast to the Syrian Arab Republic, which achieves the lowest value of 0.01\% [7], [8]. Latin America, as a developing region, has various values below $1.25 \%$, which places it at the orange-red threshold in the achievement of the Expenditure on Research and Development (GERD) indicator of SDG 9 of Global Goals [9] [10]. Adequate investment in R\&D leads to economic growth. Therefore, it leads to sustainable development by improving the rate of resource consumption, controlling climate change, reducing environmental degradation, just to name a few positive consequences [11].

The purpose of this research is to carry out a descriptive analysis of the GDE on R\&D indicator for Latin American countries [12], in the period 2008 - 2017, in order to analyze and compare it. Firstly, information is presented on the GDE on R\&D indicator. Then, the analysis and comparison of the indicator among Latin American countries is shown. In the same way, for those countries that obtain better results, they are compared with the values of the indicator of other countries of Ibero-America and North America.

\section{GDE on R\&D}

The GDE on R\&D indicator provides information on the ratio of the level of financial resources invested in R\&D, in terms (\%) of the GDP [12]. Table 1 contains the definition of the indicator given by OECD [4], UNESCO [11], RICYT [12], UN [13], World Bank [14] and OECD's Fracati Manual [15]. 
Table 1. Definitions of the GDE on R\&D indicator according to [4] [11] [12] [13] [14] [15].

\begin{tabular}{|c|c|}
\hline Definition & Source \\
\hline $\begin{array}{l}\text { Gross domestic expending on R\&D is defined as the total expenditure (current and capital) on R\&D carried out by all resident } \\
\text { companies, research institutes, university and government laboratories, etc., in a country. It includes R\&D funded from abroad, } \\
\text { but excludes domestic funds for R\&D performed outside the domestic economy. This indicator is measured in USD constant } \\
\text { prices using } 2010 \text { base year and Purchasing Power Parities (PPPs) and as percentage of GDP. }\end{array}$ & OECD (2020) [4] \\
\hline $\begin{array}{l}\text { Expenditure on Researched and Development is Gross domestic expenditure on scientific research and experimental } \\
\text { development (R\&D) expressed as a percentage of Gross Domestic Product (GDP). }\end{array}$ & UNES \\
\hline Relative effort of the country with regard to I+D, taking as a point of reference the PIB (PPPs: purchasing power parities). & RICYT (2020) [12] \\
\hline $\begin{array}{l}\text { Gross domestic expenditure on R\&D (GERD) activities as the total intramural expenditure on research and development } \\
\text { performed on the national territoy during a given period. It includes } R \& D \text { performed within a country and funded from abroad } \\
\text { but excludes payments for } R \& D \text { performed abroad. }\end{array}$ & $\mathrm{UN}(2015)[13]$ \\
\hline $\begin{array}{l}\text { Expenditures for research and development are current and capital expenditures (both public and private) on creative work } \\
\text { undertaken systematically to increase knowledge, including knowledge of humanity, culture, and society, and the use of } \\
\text { knowledge for new applications. R\&D covers basic research, applied research, and experimental development. }\end{array}$ & World Bank (2020) [14] \\
\hline $\begin{array}{l}\text { Research and experimental development is a creative work undertaken on a systemic basis in order to increase the stock of } \\
\text { knowledge, including knowledge of man, culture and society, and the use of this stock of knowledge to devise new } \\
\text { applications. R\&D covers basic research, applied research, and experimental development. }\end{array}$ & OECD's Frascati Manual (2015) [15] \\
\hline
\end{tabular}

Although the indicator does not show the proportion of expenditure on R\&D which contributes specifically to sustainable development [9], it is used to compare countries, both developed and underdeveloped, in terms of R\&D. It is also included as the GERD indicator of SDG 9 in the SDG Report 2020 [16], [17], [18]. Table 2 shows the targets and thresholds values of the indicator, highlighting the optimal value and the evaluation scale (green, yellow, orange and red) according to the range of values of the indicator [10], [16].

Table 2. SDG 9 Expenditure on Researched and Development Indicator Evaluation Scale in the SDG 2020 Report [10], [16].

\begin{tabular}{|c|c|c|c|c|c|c}
\hline & Units & $\begin{array}{c}\text { Optimum } \\
\text { (value=100) }\end{array}$ & Green & Yellow & Orange & Red \\
\hline $\begin{array}{c}\text { Expenditure on } \\
\text { research and } \\
\text { development }\end{array}$ & $\%$ of GDP & 3,7 & $\geq 1,5$ & $1,5>x \geq 1,25$ & $1,25>x \geq 1$ & $>1$ \\
\hline
\end{tabular}

Table 3 shows the values of the GDE on R\&D of Latin American countries from 2008 to 2017 [12]. The countries: EC, HN, NI, PY, PE and VE were not considered in the study because they did not present complete data [12]. The estimated values for Ibero-America, Latin America and the Caribbean are included for the analysis. Only Brazil is in the orange interval $(1.25 \%>x>1 \%)$. The rest of the Latin American countries are in the red interval $(\mathrm{x}<1 \%)$.

Table 3. GDE on R\&D of Latin American countries from 2008 to 2017 [12].

\begin{tabular}{|c|c|c|c|c|c|c|c|c|c|c|c|c|}
\hline Country & 2008 & 2009 & 2010 & 2011 & 2012 & 2013 & 2014 & 2015 & 2016 & 2017 & Average & Standard deviation \\
\hline Argentina & 0,0047 & 0,0058 & 0,0056 & 0,0057 & 0,0063 & 0,0062 & 0,0059 & 0,0062 & 0,0056 & 0,0055 & 0,0058 & 0,0004 \\
\hline Brazil & 0,0113 & 0,0112 & 0,0116 & 0,0114 & 0,0113 & 0,012 & 0,0127 & 0,0134 & 0,0126 & 0,0126 & 0,0120 & 0,0007 \\
\hline Chile & 0,0037 & 0,0035 & 0,0034 & 0,0035 & 0,0036 & 0,0039 & 0,0038 & 0,0037 & 0,0038 & 0,0036 & 0,0037 & 0,0002 \\
\hline Colombia & 0,002 & 0,002 & 0,002 & 0,0021 & 0,0023 & 0,0027 & 0,0031 & 0,0029 & 0,0027 & 0,0024 & 0,0024 & 0,0004 \\
\hline Costa Rica & 0,004 & 0,0054 & 0,0048 & 0,0048 & 0,0057 & 0,0056 & 0,0058 & 0,0045 & 0,0043 & 0,0043 & 0,0049 & 0,0006 \\
\hline El Salvador & 0,0011 & 0,0008 & 0,0007 & 0,0003 & 0,0003 & 0,0006 & 0,0008 & 0,0013 & 0,0015 & 0,0018 & 0,0009 & 0,0005 \\
\hline Guatemala & 0,0006 & 0,0006 & 0,0004 & 0,0005 & 0,0005 & 0,0004 & 0,0003 & 0,0003 & 0,0002 & 0,0003 & 0,0004 & 0,0001 \\
\hline Mexico & 0,004 & 0,0042 & 0,0049 & 0,0047 & 0,0042 & 0,0042 & 0,0044 & 0,0043 & 0,0039 & 0,0033 & 0,0042 & 0,0004 \\
\hline Panama & 0,0019 & 0,0014 & 0,0015 & 0,0017 & 0,0008 & 0,0006 & 0,0014 & 0,0012 & 0,0014 & 0,0015 & 0,0013 & 0,0004 \\
\hline Trinidad and Tobago & 0,0003 & 0,0006 & 0,0005 & 0,0004 & 0,0004 & 0,0006 & 0,0008 & 0,0009 & 0,0009 & 0,0009 & 0,0006 & 0,0002 \\
\hline Uruguay & 0,0038 & 0,0041 & 0,0034 & 0,0035 & 0,0033 & 0,0032 & 0,0034 & 0,0036 & 0,0041 & 0,0049 & 0,0037 & 0,0005 \\
\hline Latin America and the Carib] & 0,006 & 0,0062 & 0,0065 & 0,0063 & 0,0063 & 0,0066 & 0,0068 & 0,007 & 0,0066 & 0,0064 & 0,0065 & 0,0003 \\
\hline Ibero-America & 0,0076 & 0,0078 & 0,0079 & 0,0076 & 0,0075 & 0,0077 & 0,0078 & 0,0079 & 0,0076 & 0,0075 & 0,0077 & 0,0001 \\
\hline
\end{tabular}

3. GDE on R\&D of LATAM countries in the period 2008-2017

The following is a descriptive analysis of the GDE on R\&D of LATAM countries, grouping them in this way: $(\mathrm{GDE}$ on $\mathrm{R} \& \mathrm{D})<0.002 ; 0.002<(\mathrm{GDE}$ on R\&D) <0.005 and (GDE on R\&D) > 0.005, from 2008 to 2017. 


\subsection{LATAM countries with $($ GDE on $R \& D)<0.002$}

Fig. 1 shows the GDE on R\&D values of Latin American countries with (GDE on R\&D) <0.002: SV, GT and PA. Although the three countries present a value of (GDE on R\&D) less than 1 (red), Panama is that it presents an average value of $0.0013(\sigma=0.0004)$. It is followed by SV with an average value of $0.009(\sigma=0.0005)$. In last place is GT with an average value of $0.0004(\sigma=0.0001)$.

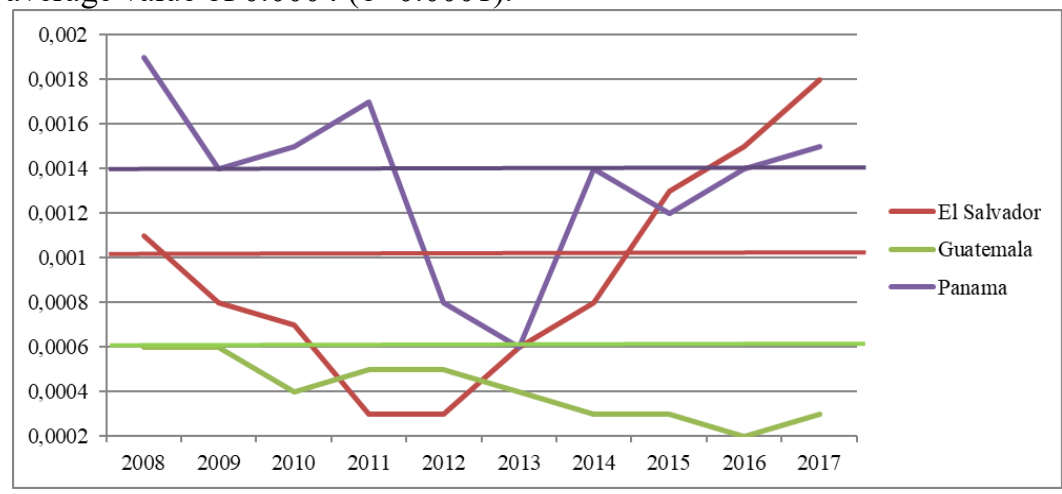

Fig 1. LATAM countries with $(G D E$ on $R \& D)<0.002$ [12].

\subsection{LATAM countries with $0.002<(G D E$ on $R \& D)<0.005$}

Fig. 2 shows the GDE on R\&D values of Latin American countries with $0.002<($ GDE on R\&D) $<0.005$ : CL, CO, CR, MX and UY. Similarly, all five countries have a value of (GDE on R\&D) less than 1 (red): CR has an average value of $0.0049(\sigma=0.0006)$. In second place is MX with an average value of $0.0042(\sigma=0.0004)$. CL and UY share the average value of 0.0037 , although with different standard deviations: $\sigma=0.0002$ and $\sigma=0.0005$, respectively. Last is $\mathrm{CO}$ with an average value of $0.0024(\sigma=0.0004)$

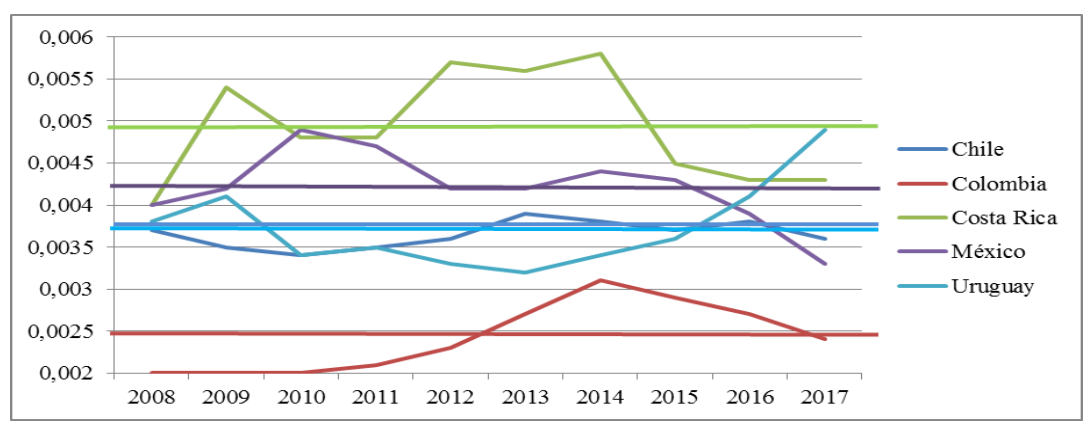

Fig 2. LATAM countries with GDE on $0.002<(\mathrm{GDE}$ on $\mathrm{R} \& \mathrm{D})<0.005$ [12].

\subsection{LATAM countries with (GDE on $\mathrm{R} \& D)>\mathbf{0 . 0 0 5}$}

Fig. 3 shows the GDE on R\&D values of Latin American countries with (GDE on R\&D) > 0.005: BR and AR. BR is the only Latin American country that presents: 1) an average value of (GDE on R\&D) $>1$ (orange): $0.012(\sigma=0.0007)$, and 2) its location above the average value of Latin America and the Caribbean $(0.0065$ and $\sigma=0.0003)$. It is followed by AR with an average value of $0.0058(\sigma=0.0004)$.

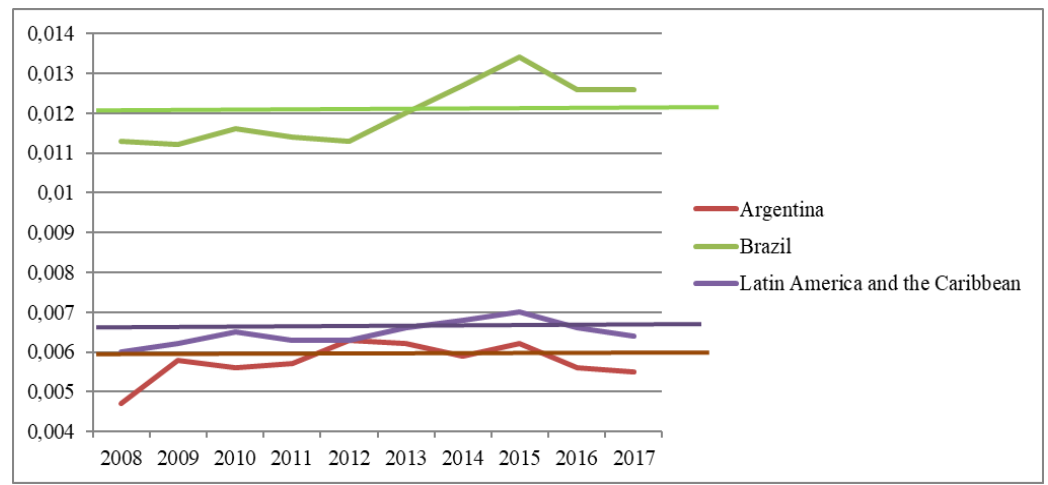

Fig 3. LATAM countries with (GDE on R\&D) > 0.0050 [12]. 
3.4 Comparison of GDE on R\&D in Brazil with LATAM and the Caribbean, North America and Ibero-America countries

Table 4 shows the average values and standard deviation of GDE on R\&D for BR, US, CA, PT, ES, IberoAmerica, Latin America and the Caribbean. Fig. 4 shows the comparison of Brazil, with an average value of $0.0020<(\mathrm{GDE}$ on R\&D) $<0.005$ (orange), with the countries from LATAM and the Caribbean, North America and Ibero-America:

1. Regarding LATAM and Caribbean countries: despite the fact that BR is a country belonging to this region, in the 2008-20017 period, it has maintained a GDE on R\&D value above the value of LATAM and the Caribbean (0.0065). There is a gap in favor of BR of 0.0055 on average.

2. Regarding North American countries: BR's GDE on R\&D has been below the US and CA values in the period considered. With respect to the US, the difference is -0.0154 . With CA, the difference is -0.0056 , on average.

3. Regarding Ibero-American countries: BR's GDE on R\&D is below the values of PT and SP: -0.0019 and -0.0008 , on average. Nevertheless, BR has a GDE on R\&D value above the Ibero-American average (0.0077), with a gap of 0.0043 on average.

Table 4. Average values and standard deviation of GDE on R\&D from BR, US, CA, PT, SP, IberoAmerican, Latin American and Caribbean countries [12].

\begin{tabular}{|l|l|l|}
\hline Country & Average & $\begin{array}{l}\text { Standard } \\
\text { desviation }\end{array}$ \\
\hline United States & 0,0274 & 0,0003 \\
\hline Canada & 0,0176 & 0,0009 \\
\hline Portugal & 0,0139 & 0,0011 \\
\hline Spain & 0,0128 & 0,0006 \\
\hline Brazil & 0,0120 & 0,0007 \\
\hline Ibero-America & 0,0077 & 0,0001 \\
\hline Latin America and the Caribbean & 0,0065 & 0,0003 \\
\hline
\end{tabular}

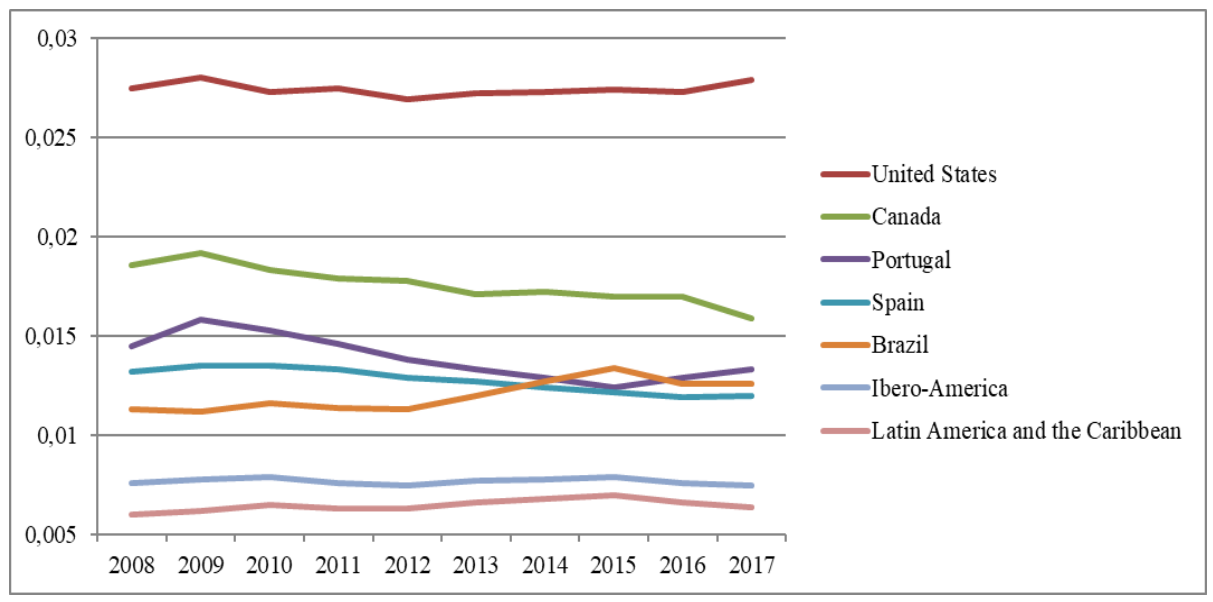

Fig 4. Brazil: LATAM country with $0.0020<($ GDE on $\& \& D)<0.005$ (orange) when compared to LATAM and the Caribbean, North American and Ibero-American countries [12].

\section{Conclusions}

The Gross Domestic Expenditure on R\&D indicator provides information on the level of financial resources invested in R\&D as a percentage of GDP. countries with the best values for this indicator are approaching the SDG 9 goal. Therefore, these countries are approaching to an ensuring sustainable development, framed in the UN Global Goals

With respect to Latin American countries, the first thing that stands out is the lack of updated information regarding the GDE on R\&D indicator. Second, most countries have an indicator value below 0.01 (red): SV, GT and PA are below 0.002 on average. CL, CO, CR, MX and UY have average values between $0.002<$ (GDE on $\mathrm{R} \& \mathrm{D})<0.005$. AR is at 0.0058 . 
For BR, the indicator is located on the orange scale of SDG 9 in the SDG Report 2020: 0.012 on average (above the average value for Latin American and Caribbean and Ibero-American countries) with average gaps of 0.0055 and 0.0043 , respectively. With respect to US and CA, the BR indicator is below, with average negative differences of -0.0154 and -0.0056 .

\section{References}

1. Quinde-Rosales, V., Bucaram, R., Bucaram-Leverone, M. \& Silvera, C.: Relationship between spending on Science and Technology and Gross Somestic Product. An empirical analysis between Latin America and the Caribbean and Ecuador. Espacios. 40.7. (2019).

2. Vásquez, C., Torres-Samuel, M., \& Viloria, A.:Public policies in science and technology in Latina American Contries with Universitiers in the Top100 of Web Ranking. Journal of Enginerring an Applied Sciences. 12 (11) p. 2963. (2017).

3. Campo, J. \& Mendoza, H.: Gasto público y crecimiento económico: un análisis regional para Colombia, 1984-2012. Lecturas de Economía, 88 (enero - junio), 77-108, Universidad de Antoquia, (2018).

4. OECD Homepage, Gross domestic spending on R\&D (indicator), https://data.oecd.org/rd/grossdomestic-spending-on-r-d.htm, last accessed 2020/09/12.

5. Lafortune, G., Fuller, G., Moreno, J., Schmidt-Traub, G. \& Kroll, C. (2018).SDG Index and Dashboards. Detailed Methodological paper. https://dashboards.sdgindex.org/downloadsr.

6. Karczewska, M., Gross domestic expenditure on research and development in GDP of European union countries- changes in trends. Regional Economy in Theory and Practice, 286, 121-132, (2013).

7. UNESCO Homepage. https://whc.unesco.org/en/list/, last accessed 2020/09/07.

8. IndexMundi Homepage. Research and development Spending (\% GDP). https://www.indexmundi.com/es/datos/indicadores/GB.XPD.RSDV.GD.ZS

9. UN https://www un org/esa/sustdev/natlinfo/indicators/methodology sheets/econ_development/resesarch_d evelopment_expenditure.pdf, last accessed 2020/09/12.

10. Sachs, J., Schmidt-Traub, G., Kroll, C., Lafortune, G., Fuller, G. \& Wowlm, F. (2020). The Sustainable Development Goals and COVID-19. Sustainable Development Report 2020. Cambridge: Cambridge University Press.

11. UNESCO, Welcome to UIS.Stat, http://data.uis.unesco.org/Index.aspx, last accessed 2020/09/15.

12. RICYT Homepage, Gasto en I+D con relación al PIB 2008-2017, http://app.ricyt.org/ui/v3/comparative.html?indicator=GASTOxPBI\&start_year=2008\&end_year=2017, last accessed 2020/09/12.

13. United Nations (2015). Industries, Innovation and Infrastructure. Sustainable Development Goals Homepage, https://www.un.org/sustainabledevelopment/infrastructure-industrialization/, last accessed 2020/09/06.

14. The World Bank Homepage, TCdata360, https://tcdata360.worldbank.org/indicators/GB.XPD.RSDV.GD.ZS? country=BRA\&indicator=2013\&vi z=line_Table\&years=1996,2017, last accessed 2020/09/12.

15. OECD, Frascatti Manual, Guidelines for collecting and reporting data on research and experimental development, https://www.oecd.org/sti/inno/frascati-manual.htm, last accessed 2020/09/1.

16. United Nations, The Sustainable Development Goals Report 2020, United Nations. New York. Available in: https://unstats.un.org/sdgs/report/2020/, last accessed 2020/09/08.

17. SDG Index and Dashboards. Detailed Methodological paper. https://dashboards.sdgindex.org/downloadsr.

18. United Nations, Sustainable Development Homepage, https://dashboards.sdgindex.org/rankings, last accessed 2020/09/09. 